\title{
A IMPORTÂNCIA DA \\ SUSTENTABILIDADE E DA \\ EDUCAÇÃO AMBIENTAL NAS \\ DISCUSSÕES SOBRE A \\ PROBLEMÁTICA \\ SOCIOAMBIENTAL DA CIDADANIA \\ EM ESCOLAS PÚBLICAS
}

Isabelle Déjardin ${ }^{1}$

Resumo: Este artigo objetivou analisar a importância da sustentabilidade, da educação ambiental e do meio ambiente nas discussões sobre a problemática socioambiental da cidadania em escolas públicas. Foram consideradas as práticas de educação ambiental nos contextos escolares bem como uma análise geral dos princípios de cidadania e meio ambiente apresentados nos documentos oficiais. O texto inicia-se com um breve histórico sobre a sustentabilidade e o desenvolvimento sustentável na contemporaneidade. Por meio de pesquisa exploratória e bibliográfica, foram destacados os principais elementos teóricos, metodológicos e epistemológicos que compõem o cenário investigado.

Palavras-chave: Problemática Socioambiental da Cidadania; Educação Ambiental; Sustentabilidade; Meio Ambiente.

${ }^{1}$ Universidade Federal da Bahia. E-mail: belledejardin@hotmail.com

Revbea, São Paulo, V. 11, № 5: 67-88, 2016.

revista brasileira educação ambiental 


\section{Introdução}

Como tem sido discutida a problemática socioambiental da cidadania no âmbito das escolas públicas? Qual a importância da sustentabilidade, da educação ambiental e do meio ambiente nesse contexto formativo? $\mathrm{Na}$ perspectiva de perscrutar o tema em meio ao conhecimento produzido, isso implica algumas considerações sobre as práticas de educação ambiental nos contextos escolares bem como uma análise geral dos princípios de cidadania e meio ambiente apresentados nos documentos oficiais. Incluindo, inicialmente, um breve histórico sobre a sustentabilidade e o desenvolvimento sustentável na contemporaneidade. Assim, no presente artigo, é utilizada a expressão "problemática" para explicitar a perspectiva complexa, conflituosa e contemporânea das questões socioambientais imbricadas na cidadania. A noção de problematização em um contexto de complexidade - mas não de complicação - é algo que nos estimula a agir e a produzir conhecimentos, surgindo da "indignação, do espanto e do encantamento diante dos conflitos da existência que, desde que contextualizados, podem ser compreendidos de maneira saudável em suas multiplicidades complexas" (PETRAGLIA, 2008, p. 36).

Com isso, torna-se necessário refletir sobre as possibilidades de que uma única explicação ou método, ancorado apenas nessa ou naquela ciência, possa ser capaz de expressar um fenômeno complexo dessa magnitude. Para descrever o desenrolar sócio histórico que culminou, em pleno séc. XXI, no emaranhado teórico-metodológico desses temas, é possível recorrer ao pensamento complexo de Morin (2003, p. 89), no qual se há, efetivamente, a premência de: a) compreender que o conhecimento das partes depende do conhecimento do todo e que o conhecimento do todo depende do conhecimento das partes; b) reconhecer e examinar os fenômenos multidimensionais, em vez de isolar, de maneira mutiladora, cada uma de suas dimensões; c) reconhecer e tratar as realidades, que são, concomitantemente, solidárias e conflituosas, como a própria democracia, sistema que se alimenta de antagonismos e ao mesmo tempo os regula; d) respeitar as diferenças, enquanto se reconhece a unicidade.

Diante dessas premissas, por meio de pesquisa exploratória e bibliográfica (GIL, 1999), o objetivo deste artigo é analisar a importância da sustentabilidade, da educação ambiental e do meio ambiente nas discussões sobre a problemática socioambiental da cidadania em escolas públicas, destacando, em suas respectivas seções, os principais elementos teóricos, metodológicos e epistemológicos que as embasam.

\section{Breve histórico sobre o movimento ambientalista mundial}

No esforço de não isolar os acontecimentos sociais e históricos da contemporaneidade - como se os mesmos estivessem descolados do todo ou não dependessem das condições que os organizaram - recorda-se que o movimento ecológico/ambientalista esteve imerso em um contexto social e político de transformação. Com efeito, levando em conta a dimensão ecológica 
da globalização atual, dois sentidos distintos se tornam complementares: a origem transfronteiriça dos problemas ambientais, como o uso de bens ambientais, poluição e dinâmica populacional; os processos políticos e culturais decorrentes desses problemas, como as leis, tratados e debates sobre a ética ecológica (LOUREIRO et al., 2003). Isso porque as distintas percepções da crise socioambiental acabaram emergindo as causas das crises de recursos, das desigualdades do desenvolvimento econômico, da nova racionalidade produtiva fundada no potencial ambiental de cada nação, região, território, população, comunidade, gerando demandas específicas de conhecimentos práticos e teóricos, conforme destaca Leff (2011). Segundo o autor, essa problemática ecológica mobiliza um amplo processo de produção, apropriação e utilização de conceitos ambientais, que refletem as estratégias de uso e aproveitamento sustentável dos recursos.

Importante ressaltar que foi justamente a partir do movimento ambientalista que se iniciaram novos embates acadêmico-científicos e da sociedade organizada frente a uma nova consciência ecológica, sendo considerado um dos principais movimentos de caráter político-cultural da atualidade (COSTA, 2009). De fato, na esfera das relações entre natureza e sociedade, os anos 1960-1970 marcam a história do movimento ambientalista mundial. Iniciaram-se os debates políticos e acadêmicos do tema em plena efervescência de movimentos de toda ordem que eclodiam em algumas regiões do mundo, dentre as quais o Brasil. Como exemplo, citem-se o movimento feminista, o estudantil, o político, 0 da contracultura, 0 da descolonização, o dos direitos dos homossexuais, os trabalhistas, dentre muito outros. Nesse período, houve um deslocamento da ênfase do movimento operário em sua vertente marxista dominante (socialdemocrata e leninista) presente, sobretudo, no desenvolvimento capitalista do séc. XIX e primeira metade do séc. XX, criticando o modo de produção, - para a ênfase nos movimentos que elegem o cotidiano e o modo de vida como categoria central de questionamento (COSTA, 2009).

Isso se deveu, muito provavelmente, ao projeto revolucionário socialista, "que desmascarou a ideologia burguesa e o do socialismo utópico", que por sua vez construiu um socialismo científico fundado em um materialismo dialético, mas que não questionou "as formas históricas do conhecimento como raiz e causa da exploração da natureza e da submissão das culturas" (LEFF, 2011 , p. 313). Esses movimentos apontaram então outras possibilidades, outros modos de vida e cultura, encontrando-se envolvidos com variadas questões e abrangendo de forma ampla os aspectos sociais da época (COSTA, 2009). No dizer de Leff (2011, p. 309-310):

A Bomba Populacional de Paul Ehrlich (1968), o Congresso de Nice sobre Interdisciplinaridade de 1968 (APOSTELS et al., 1975), a Teoria Geral de Sistemas de Paul Bertalanffy (1968), O Homem Unidimensional de Herbert Marcuse (1968), Da Gramatologia, de Derrida (1968), A Arqueologia do Saber, de Michel Foucault (1969), são indicadores da eclosão até finais 
dos anos 60 de uma nova consciência ecológica frente ao logocentrismo, a racionalidade tecnológica e a crise do crescimento econômico e populacional. Em princípios dos anos 70, Nicolás Georgescu-Roegen (1971) publica A Lei da Entropia e o Processo Econômico e se difunde mundialmente o estudo do Clube de Roma, Os Limites do Crescimento (MEADOWS et al., 1972), marcando os limites que a natureza impõe à racionalidade econômica.

Acrescente-se o ano de 1962, em que a americana Rachel Carson publica o livro Silent Spring (Primavera Silenciosa), no qual questiona o modelo agrícola convencional e sua dependência do petróleo como matriz energética, alertando os prejuízos do uso excessivo de produtos químicos para os seres humanos e o meio ambiente (JACOBI, 2005). Steinbrenner (2011) recorda que antes de Carson, em 1864, George Perkins Marsh já havia publicado o livro Man and Nature (Homem e Natureza); porém, o contexto social, político e econômico da época parecem ter contribuído para que tivesse sido pouco difundido. Assim, em 1972, às vésperas da crise mundial do petróleo, tem-se o citado lançamento do livro "Os limites do crescimento", também chamado Relatório Meadows, organizado pelo Clube de Roma (GUDYNAS, 2004). A mensagem do estudo deste organismo foi clara: não se podia invocar um crescimento econômico permanente diante de recursos naturais limitados, inserindo a natureza, que sempre esteve fora dos debates sobre desenvolvimento econômico, no centro mesmo dessas discussões, causando grandes impactos na América Latina. Para alcançar a estabilidade econômica e ecológica, a amplitude desse estudo consistiu em propor um crescimento zero da população global e do capital industrial, com base na teoria malthusiana de crescimento demográfico (FENZL; MACHADO, 2009), para a qual os alimentos obedecem a um crescimento aritmético e a população humana, a um crescimento geométrico.

Quanto à Conferência das Nações Unidas sobre o Meio Ambiente e Desenvolvimento (CNUMAD), realizada em Estocolmo, em 1972, Leff (2011, p. 310) argumenta que foi lançada uma cruzada em prol do meio ambiente, reconhecendo-se, todavia, "que a solução da problemática ambiental implica mudanças profundas na organização do conhecimento". Desse modo, o paradigma de um caminho intermediário - na forma de um ecodesenvolvimento ou desenvolvimento sustentável - propunha um desenvolvimento que harmonizasse os objetivos sociais, ambientais e econômicos (JACOBI, 2005, p. 236). De um lado, posicionavam-se os desenvolvimentistas, que priorizavam o desenvolvimento a todo custo e o crescimento econômico; de outro, os fundamentalistas ecológicos, com a estagnação do crescimento do consumo e o esgotamento dos recursos naturais, o que implicava a adoção de um paradigma de meio termo entre tais propostas.

A temática ambiental passou então ao primeiro plano, se fazendo explícita sua relação com o desenvolvimento, culminando na discussão sobre a 
responsabilidade dos países industrializados e nos problemas de contaminação, bem como nas consequências do crescimento populacional (GUDYNAS, 2004). Apesar da Conferência de Estocolmo ter sido um marco no movimento ambientalista, com a participação de 113 países, vale destacar que países em desenvolvimento (como o Brasil) "estavam mais preocupados com suas políticas de crescimento do que com os custos da poluição", como lembra Steinbrenner (2011, p. 56). No que tange o Ecodesenvolvimento ${ }^{2}$, proposto por Maurice Strong e desenvolvido por Ignacy Sachs em princípios da década de 1970, enfatiza-se a crítica às políticas que separavam o crescimento econômico dos problemas sociais e ambientais, considerando o Estado e a sociedade civil como fundamentais para fiscalizar e corrigir distorções do mercado, conforme Fenzl e Machado (2009). Segundo Jacobi (2005), os princípios difundidos em 1973 com o surgimento do ecodesenvolvimento se integrariam à Comissão Brundtland, em 1987, ressaltando as suas cinco dimensões: a sustentabilidade social; a sustentabilidade econômica; a sustentabilidade ecológica; a sustentabilidade espacial e a sustentabilidade cultural.

Ao contrário do ecodesenvolvimento, termo que acabou sobrevivendo por pouco tempo - a despeito de sua riqueza conceitual e da proposta inovadora em minimizar os danos socioambientais do modelo convencional de desenvolvimento econômico no campo das ciências, da produção material, das tradições culturais e das relações sociais -, o desenvolvimento sustentado acabou ganhando maior notoriedade. Ocorreu por ter sido adotado em importantes documentos, como a Estratégia Mundial da Conservação ${ }^{3}$, em 1980; o informe Nosso Futuro Comum, da Comissão Brundtland, em 1987; Cuidar da Terra, da UICN (União Internacional para a Conservação da Natureza), WWF (antes conhecido como Fundo Mundial para a Natureza) e PNUMA (Programa das Nações Unidas para o Meio Ambiente), em 1991; e o Informe da Comissão de Desenvolvimento e Meio Ambiente da América Latina e Caribe, em 1991 (DIEGUES, 2003). De acordo com Diegues (2003), o conceito mais difundido sobre desenvolvimento sustentável acabou sendo o da Comissão Brundtland, conhecido pelo sobrenome da primeira Ministra da Noruega, Gro Harlem.

A despeito de uma maior "publicização" da questão ambiental, que alimentou uma nova visão ambiental (LIMA, 2009), uma das maiores críticas

\footnotetext{
2 Além do ecodesenvolvimento, surgiram outras importantes alternativas, como a economia ecológica, com Herman Daly, e a Deep Ecology (ecologia profunda), com Arne Naess (FENZL; MACHADO, 2009).

3 De forma oficial, o conceito de sustentabilidade foi introduzido em 1980, no encontro internacional The World Conservation Strategy, possuindo três principais pilares: a preservação de processos ecológicos, como a água, o ar e os solos não poluídos; a exploração sustentável de recursos naturais; a conservação da biodiversidade. Para saber mais, consultar: UICN. Stratégie mondiale de la conservation: la conservation des ressources vivantes au service du développement durable. Gland: UICN, PNUE, WWF, 1980.
} 
apontadas sobre o Relatório Brundtland diz respeito à concepção de desenvolvimento como estratégia para obter qualidade de vida, já que promovida sob os moldes do desenvolvimento alcançado pelos países industrializados, no que preza a produção excessiva de bens de consumo com base em fontes de energia não renováveis e intensivas em recursos naturais.

\section{Novos rumos para a sustentabilidade, a educação ambiental e o socioambientalismo}

Levando em conta as diferentes facetas do desenvolvimento sustentável, os anos 1990 marcam as mudanças significativas no debate internacional sobre as questões ambientais, tendo com marco a Rio-92, conhecida como Eco-92 ou Cúpula da Terra. Nesta, 179 países representados por 106 chefes de governos se reúnem no Rio de Janeiro para a CNUMAD, tendo sido feitos alguns acordos que compuseram a Agenda 21, a Declaração do Rio sobre o Meio Ambiente e o Desenvolvimento, surgindo, com isso, os princípios de sustentabilidade. Conforme Jacobi (2005, p. 239), nesse rol, inclui-se a Carta da Terra, surgida após mobilização e articulação da sociedade civil, iniciada desde o documento Nosso Futuro Comum, em 1987. Porém, discutida apenas em sua primeira versão oficial na Eco-92, durante o fórum global de ONGs, tendo sido ratificada em 2000, pela Organização das Nações Unidas para a Educação, a Ciência e a Cultura (UNESCO).

Apesar de o objetivo maior ter sido a institucionalização das questões ambientais, os resultados da Rio-92 ficaram longe do esperado pelos organismos que a propuseram, ainda que adotados como referenciais nos debates e discussões que se seguiram, como destaca Jacobi (2005). O autor diz que os avanços produzidos desde então se reduziram drasticamente antes e após a Cúpula Mundial sobre Meio Ambiente e Desenvolvimento Sustentável, chamada Rio+10, realizada em 2002, na cidade de Johanesburgo, na África do Sul. Mesmo considerando os avanços, vale lembrar que no séc. XXI os princípios de proteção ambiental ainda são vistos pelos países em desenvolvimento como um obstáculo ao crescimento econômico, acarretando perda de biodiversidade, injustiças sociais, degradação da qualidade urbanoambiental e redução de recursos não renováveis. Com isso, não seria mais possível que a discussão contemporânea sobre a construção de sociedades sustentáveis isolasse, fragmentada e separadamente, as questões ambientais das sociais.

No Brasil, durante muito tempo, estas questões foram consideradas inconciliáveis, tanto nos discursos que tratavam sobre pobreza e desenvolvimento quanto nos que tratavam de meio ambiente, constituindo, posteriormente, no que se denomina de socioambientalismo (LIMA, 2011). Conforme Oliveira et al. (2007), autores que elaboraram uma pesquisa sobre a cidadania socioambiental infanto-juvenil, a abordagem dos problemas ambientais brasileiros - até meados dos anos 1980 - esteve dissociada das questões sociais, culturais, políticas e econômicas, mostrando-se restrita às

Revbea, São Paulo, V. 11, № 5: 67-88, 2016. 
contribuições da ciência. Esse ambientalismo configurava-se mais pelo viés técnico-científico do que pela complexidade dos conflitos ambientais; complexidade esta que envolvia comunidades diversas, interesses díspares, decisões políticas e sujeições econômicas. Foi preciso levar em conta o reconhecimento de que tanto o direcionamento das políticas públicas a serem tomadas quanto a gestão do meio ambiente deveriam estar implicados nos processos decisórios democráticos.

Por isso, seria possível admitir que a sustentabilidade fosse dependente dos movimentos sociais e das articulações com outros setores, inclusive os econômicos.

[...] as condições e possibilidades para o exercício da cidadania no âmbito das questões ambientais beneficiou-se da transição para o socioambientalismo, entendido como um contexto favorecedor das práticas cidadãs ao estimular a democratização da gestão ambiental (OLIVEIRA et al., 2007, p. 5).

Lima (2011) explica que, no Brasil, com o avanço do discurso ambientalista por setores diversos, seus princípios acabaram sendo difundidos e reapropriados, tendo na contradição um de seus maiores dilemas, que consiste na dualidade entre realizar uma sustentabilidade democrática, plural e emancipatória em um contexto dominado pelas forças de mercado. Assim, o processo de institucionalização das questões ambientais na contemporaneidade apontou para as duas principais direções na qual ocorreu: a primeira, pela expansão da informação (ainda que parcial e superficial), da problematização e da consciência ambiental, atingindo novos setores sociais e ganhando status na agenda político econômica; a segunda, "no sentido da diluição dos conteúdos críticos do ambientalismo original e na substituição da perspectiva do conflito por uma perspectiva conciliatória" (LIMA, 2011, p. 128).

Para instituir a sustentabilidade como um novo paradigma, políticas públicas tornar-se-iam prementes, como a presença do Estado, a oferta de bens públicos e a consolidação de instituições democráticas, incluindo o acesso à educação e ao conhecimento produzido. Dessa condição, surgiriam as diversas possibilidades de interação - no âmbito educacional e socioambiental - entre esferas sociais, tais como o próprio Estado, a sociedade civil, Organizações Não Governamentais (ONGs), igrejas, associações comunitárias, instituições de ensino, universidades e centros de pesquisa, entre outras. Nessa perspectiva, Lima (2009, p. 149) destaca três influências específicas no primeiro momento da formação do campo da educação ambiental no Brasil, nos idos dos anos 1970: as pressões dos organismos internacionais sobre o governo para instituir órgãos e políticas públicas ambientais; a ação da sociedade civil por intermédio dos movimentos sociais e das ONGs; as iniciativas pioneiras de escolas e educadores inspirados por essa "motivação renovadora". De acordo com o autor, desde essa época, a 
educação ambiental vem se constituindo como um campo de conhecimento e de atividade política e pedagógica, marcada por um caráter plural e complexo, ao reunir contribuições de variadas disciplinas científicas. Isso inclui matrizes filosóficas, posições político-pedagógicas, atores e movimentos sociais.

Essa dinâmica é verificada pelas palavras de Leff (2011, p. 310), quando cita os programas e conferências internacionais sobre educação ambiental desse período, ressaltando, inclusive, o caráter complexo e interdisciplinar dos problemas ambientais:

Assim, em 1975 se estabelece o Programa Internacional de Educação Ambiental (PIEA), patrocinado pela UNESCO e pelo Programa das Nações Unidas para o Meio Ambiente (PNUMA). Mais tarde, na Conferência Intergovernamental sobre Educação Ambiental, celebrada em Tbilisi em 1977, estabelecem-se as orientações gerais da educação ambiental, fundada em princípios da interdisciplinaridade como método para compreender e restabelecer as relações sociedadenatureza (UNESCO, 1980) ${ }^{4}$. O PIEA buscou incorporar uma 'dimensão ambiental' nas diferentes disciplinas, assim como nos métodos de investigação e nos conteúdos do ensino formal e informal. Nessa perspectiva, reconhece-se que os problemas ambientais são sistemas complexos, nos quais intervêm processos de diferentes racionalidades, ordens de materialidade e escalas espaço-temporais.

A educação ambiental agregou muitas discussões sobre uma educação voltada para a cidadania, enfatizando os temas para reflexão e debate do cidadão-crítico, ou do sujeito-cidadão-ativo, que deveria estar comprometido com uma práxis transformadora. Na proposta de Tbilisi, conforme citado por Leff (2011), o enfoque consistia em englobar a solução de problemas, como a educação interdisciplinar, a integração da educação na comunidade e uma educação voltada para o futuro. Estes são pontos passivos de análise quando se reflete uma educação ambiental cidadã em um contexto formativo. Ressaltase, nesse sentido, o que informa o Fórum Internacional de Organizações Não Governamentais e Movimentos Sociais (1992), que propõe o Tratado de Educação Ambiental para Sociedades Sustentáveis e Responsabilidade Global, segundo o qual a educação ambiental associa-se à sustentabilidade, afirmando que a educação ambiental para uma sustentabilidade equitativa é um processo de aprendizagem permanente, com base no respeito a todas as formas de vida. Ora, essa educação deve afirmar valores e ações que contribuam efetivamente para a transformação humana e social e para a preservação ecológica, não pressupondo, obviamente, a mera reprodução das condições dominantes.

${ }^{4}$ Para saber mais, ver: UNESCO. La educacíon ambiental: las grandes orientaciones de La Conferencia de Tbilisi. Paris: 1980.

Revbea, São Paulo, V. 11, № 5: 67-88, 2016. 
Tal processo objetiva influenciar a formação de sociedades socialmente justas e ecologicamente equilibradas, podendo conservar entre si a relação de interdependência e diversidade. Para tanto, são requeridas as responsabilidades individual e coletiva em nível local, nacional e planetário, conforme enfatiza o Fórum Internacional de Organizações Não Governamentais e Movimentos Sociais (1992). No que comenta Ayres (2007), insere-se a problemática socioambiental da cidadania, quando o autor lembra que a própria Comissão Interministerial ligada a Rio-92 iria incorporar a dimensão cultural, histórica, política e socioeconômica, afirmando que a educação ambiental deve possibilitar o entendimento da natureza complexa do meio ambiente, implicando a interdependência entre os seus diversos elementos. Desse modo, visa-se o uso adequado dos recursos naturais e a capacitação para o exercício pleno da cidadania, na satisfação material e espiritual das necessidades atuais e futuras, no contexto de uma educação comprometida, ao mesmo tempo, com as mudanças sociais, ambientais e culturais.

Esse pensamento possui relação intrínseca com os pressupostos de uma sociedade não estática e tensionada com os aspectos sociais e históricos que compõem a realidade complexa, conforme observa Loureiro (2005), quando o mesmo distingue o "todo" do "tudo" na interpretação da teoria da complexidade de Morin. Segundo Loureiro et al. (2003), o discurso de uma sociedade sustentável, apoiando-se em uma nova forma de compreender o mundo, pressupõe a crítica às relações sociais, mas também ao sentido, ao valor e ao uso dado à natureza, o que implicaria superar o que se entende como "nefasto" para a manutenção do planeta e da felicidade humana. Os autores comentam que a busca pela felicidade e liberdade humanas se associa ao projeto de redefinição de nosso pertencimento à natureza.

Conforme Diegues (2003), em se tratando de uma ética do cuidado, na esfera ambiental a natureza tem direito à existência, afirmando o valor intrínseco do mundo natural e de suas formas de vida, incluindo-se a humana. Por seu turno, os princípios sociopolíticos são traduzidos na distribuição equitativa da riqueza gerada, a participação das populações nas decisões das coisas públicas, as liberdades democráticas e a satisfação das necessidades básicas. Diante dessas duas assertivas, percebem-se complementaridades e antagonismos na esfera ambiental e nos princípios sociopolíticos, conforme a evidente incompatibilidade histórica entre a necessidade e o desejo em desenvolver econômica e socialmente, exercer a cidadania e preservar a natureza. No processo de expansão da cidadania, novos debates se configuram, traçando caminhos múltiplos, singulares e complexos para a problemática socioambiental da cidadania nas escolas públicas brasileiras, trazendo à tona a importância da sustentabilidade, da educação ambiental e do meio ambiente nesse contexto formativo. 


\section{Problemática socioambiental da cidadania: desafio para a educação}

Com efeito, destaca-se, inicialmente, o que afirma Lima (2009, p. 152), quando recorda que a educação é um "subsistema que se subordina e articula ao macrossistema social', fazendo com que concepções e práticas educacionais estejam contidas em um dado contexto histórico mais amplo, e "que condiciona seu caráter e sua direção pedagógica, política e cultural". Segundo Lima (2009, p. 152), o processo educativo não é algo que comporta, em seus pressupostos, neutralidade e objetividade, estando totalmente livre de interesses, ideologias e valores dominantes; ao invés, "é uma construção social repleta de subjetividade, de escolhas valorativas e de vontades políticas dotado de uma especial relevância social por sua capacidade de reproduzir ou transformar a ordem social".

De acordo com Lima (2009), o propósito do processo educativo é favorecer um envolvimento efetivo com a socialização e a formação de indivíduos e de sua identidade social e cultural, tendo em vista que a educação pode apresentar um papel conservador perante a ordem social, ao reproduzir valores, ideologias e interesses daqueles que detêm poder. Como uma via de mão dupla, a educação também se propõe a um papel emancipatório, na medida em que os valores culturais, éticos e políticos das sociedades estejam relacionados com o desenvolvimento das potencialidades dos sujeitos (LIMA, 2009).

Em nosso país, entretanto, isso representa uma dicotomia aparentemente não superada pela prática educativa, como se pode observar pela existência de diferentes entraves culturais e socioeconômicos presentes nas escolas públicas, impactando as interações entre os sujeitos e a emancipação dos discentes no acesso ao conhecimento produzido pelas comunidades científicas. Nesse percurso de intenções e possibilidades, as mudanças não foram claramente percebidas, se considerarmos a escola como um lócus aberto às diferenças socioculturais para a construção e socialização de conhecimentos, de saberes e de sentidos. Não se pode conceber uma escola centrada na transmissão de velhos conceitos, valores e normas sem integração com a realidade de seus alunos.

Nas palavras de Freire (1987), uma escola que não esteja integrada com a realidade vivenciada pelos seus educandos torna-se vazia de sentidos, considerando que a maioria dos conteúdos discutidos em sala de aula acaba sendo retalhada da realidade dos sujeitos e da totalidade de significados das coisas e acontecimentos. Sendo assim, a educação vai se tornando reprodutora de conceitos abstratos e rígidos que se encontram desprovidos de significado e de poder transformador. É nesse momento que o processo de "narração" desses conteúdos - feita a partir dos professores para com os educandos - irá servir mais para transmitir-Ihes algo do receituário do que para buscar concretamente conhecimentos. Sem a intenção de invalidar a primeira proposição, o que se pretende é oferecer alternativas para os educandos. 
Essas ideias constituem parte dos conceitos de educação bancária amplamente criticada por Freire (1987, p.58):

Dessa maneira, a educação se torna um ato de depositar, em que os educandos são os depositários e o educador o depositante [...] em lugar de comunicar-se, o educador faz 'comunicados' e depósitos que os educandos, meras incidências, recebem pacientemente, memorizam e repetem.

Como reitera Demo (2000, p.33):

Se buscamos uma cidadania emancipada, capaz de projeto próprio de desenvolvimento [...] o instrumento mais decisivo, hoje, é a habilidade de manejar e produzir conhecimento. Se educação se diz emancipatória, não poderá prescindir de lançar mãos deste meio. Não corresponderá ao desafio da cidadania moderna, se permanecer na mera transmissão, cópia, reprodução de conhecimento, no puro ensino e na pura aprendizagem, nos treinamentos domesticadores.

Por outro lado, se o objetivo primordial da escola é propiciar o compartilhamento, a organização, a sistematização, o diálogo e a compreensão do conhecimento produzido, os processos educativos também comportam a dinâmica daquilo que se pretende socializar, buscando novas formas de potenciar essa apropriação. Nesse âmbito, encontra-se o "saber pensar", virtude de quem está à frente do seu destino e possui autonomia para garantir a participação na cidadania, como bem acrescenta Demo (2000), quando trata da construção do conhecimento na atualidade. Por isso, "a aventura de construir conhecimento é tipicamente a aventura dos tempos modernos, num conluio surpreendente entre inteligência crítica e criativa humana e meios eletrônicos socializadores" (DEMO, 2000, p. 16). O autor destaca que um dos grandes desafios do desenvolvimento humano sustentado, em especial em países como o Brasil, com elevados níveis de atraso educacional, é buscar caminhos alternativos rumo à qualidade da cidadania. Ou seja, uma cidadania ativa, participativa e que exija das instâncias governamentais melhorias educacionais na produção e acesso ao conhecimento.

Para Galeffi (2011), que transita entre a educação e os saberes plurais, é na esfera do desenvolvimento humano sustentável que a educação incorpora saberes e fazeres dos sujeitos implicados. Conforme o autor, o conhecimento difundido não é o mesmo que o meramente transmitido, consistindo em um processo sistematizado de produção do "fazer" e do "saber fazer", do "conhecer" e do "saber conhecer" (GALEFFI, 2011). Nessa vertente, o autor relaciona a difusão do conhecimento com o desenvolvimento humano sustentável. Produzindo e compartilhando conhecimentos e fazeres, comunidades escolares se inscrevem em uma dinâmica de afeto, motivação e criatividade, sem desconsiderar alguns elementos contraditórios inerentes aos 
processos pedagógicos, como os conflitos e antagonismos emergidos das relações entre sujeitos.

Quando Morin (2000) aponta os sete saberes necessários à educação do futuro, enseja uma educação contextualizada, recordando que o planeta necessita dessa compreensão mútua para que sejam construídas a democracia e a cidadania terrena e para que a humanidade possa atingir alguns dos objetivos propostos, como a convivência e o respeito entre os indivíduos. Também a discussão das questões socioambientais nos contextos escolares suscita ações de convívio e respeito mútuo nesses espaços coletivos, contribuindo para que a cidadania se torne efetivamente mais próxima desses sujeitos e de suas próprias realidades. Com efeito, ainda que de forma fragmentada, a cidadania e as questões socioambientais têm sido incorporadas nos processos educativos, ora por meio dos documentos e propostas oficiais das políticas públicas que norteiam o sistema educacional brasileiro, ora nas propostas contidas nos currículos e práticas educativas recorrentes. Nesse quesito, vale dizer que tanto os documentos públicos oficiais quanto as práticas educativas contemporâneas buscam promover a ideia da formação de sujeitos para a cidadania, ou a formação de sujeitos cidadãos.

Para tanto, tem-se a Lei de Diretrizes e Bases da Educação Nacional (LDB - Lei no 9.394/1996), conhecida como Lei Darcy Ribeiro, que em seu artigo 22 indica que a educação básica da qual o ensino fundamental é parte integrante "deve assegurar a todos a formação comum indispensável para o exercício da cidadania e fornecer-lhes meios para progredir no trabalho e em estudos posteriores [...]". Com efeito, em uma citação de Severo (2008), podese confirmar a ideia da formação de sujeitos cidadãos nos documentos oficiais, incluindo os livros didáticos e os Parâmetros Curriculares Nacionais (PCN):

A preocupação com a formação de sujeitos-cidadãos é central nos Parâmetros Curriculares Nacionais. [...] a importância conferida ao tema da cidadania e à formação de cidadãos fica evidenciada em diversos tópicos presentes nos PCN: nos objetivos gerais do ensino fundamental, na função da escola, nos conteúdos, nos temas transversais, na formação para o trabalho, no desenvolvimento das capacidades do estudante, na auto-avaliação e nas orientações didáticas. Não se pode negar que a preocupação com a formação de sujeitos-cidadãos é o foco norteador dos documentos oficiais do governo nacional sobre o ensino (SEVERO, 2008, p. 2). 
para os professores do terceiro e quarto ciclo do ensino fundamental $\left(6^{\circ}, 7^{\circ}, 8^{\circ}\right.$ e 9ano, dois anos para cada ciclo) é representar o apoio às discussões e ao desenvolvimento do projeto educativo nas escolas, incluindo a reflexão sobre a prática pedagógica, o planejamento de aulas, análise e seleção de materiais didáticos e recursos tecnológicos, bem como uma contribuição à sua formação e atualização profissional. Em relação ao alunado, a proposta é que esses parâmetros representem a necessidade de construção de uma referência curricular nacional, garantindo a todo estudante do país, independentemente da região da qual seja proveniente, o acesso aos conhecimentos indispensáveis para a construção de sua cidadania.

Em relação às escolas, os $\mathrm{PCN}$ buscam ressaltar o seu papel na sociedade brasileira, almejando os objetivos nos nove anos do ensino fundamental ${ }^{5}$. Os PCN encontram-se estruturados em dois principais pilares: a interdisciplinaridade e a contextualização. Desse modo, o ensino deve considerar a realidade de cada região e as experiências adquiridas pelos alunos, estimulando-os a atuarem como cidadãos. A ideia é que o aprendizado tenha significado e relevância para esse alunado. Quanto às questões socioambientais, em geral, surgem associadas a orientações e práticas de educação ambiental, configurando-se nas produções acadêmicas sobre contextos escolares e nos documentos oficiais. Tais premissas podem ser conferidas nas citações expressas, respectivamente, pelos documentos que compõem os PCN e os Temas Transversais das escolas públicas brasileiras, elaborados pelo Ministério da Educação (MEC).

A principal função do trabalho com o tema Meio Ambiente é contribuir para a formação de cidadãos conscientes, aptos a decidir e atuar na realidade socioambiental de modo comprometido com a vida, com o bem-estar de cada um e da sociedade, local e global. Para isso, é necessário que, mais do que informações e conceitos, a escola se proponha a trabalhar com atitudes, com formação de valores, com o ensino e aprendizagem de habilidades e procedimentos. Esse é um grande desafio para a educação (BRASIL, 1998a, p. 67-68; BRASIL, 1998b, p. 187, grifo nosso).

A solução dos problemas ambientais tem sido considerada cada vez mais urgente para garantir o futuro da humanidade e depende da relação que se estabelece entre sociedade/natureza, tanto na dimensão coletiva quanto na individual. Essa consciência já chegou à escola e muitas iniciativas têm sido tomadas em torno dessa questão, por educadores de todo o país. Por essas razões, vê-se a

5 As áreas de conhecimento dos PCN são: Língua Portuguesa, Matemática, História, Geografia, Ciências Naturais, Educação Física, Arte e Língua Estrangeira (BRASIL, 1998a, p. 58). 
importância de incluir Meio Ambiente nos currículos escolares como tema transversal, permeando toda prática educacional. É fundamental, na sua abordagem, considerar os aspectos físicos e biológicos e, principalmente, os modos de interação do ser humano com a natureza, por meio de suas relações sociais, do trabalho, da ciência, da arte e da tecnologia (BRASIL, 1998b, p. 169, grifo nosso).

Pelo que dizem esses documentos (BRASIL, 1998a; BRASIL, 1998b), a realidade socioambiental deve ser apreendida pelos sujeitos através da educação, tendo em vista que esta contribui para formar cidadãos aptos a intervir nos problemas socioambientais de cunho local e global. Com isso, são enfatizadas as atitudes individuais e coletivas na formação de valores para a cidadania, incluindo a necessidade de considerar a realidade socioambiental e as relações desenvolvidas com a natureza. Infere-se, portanto, que o objetivo seja formar cidadãos para a vida e para o mundo, capazes de atuarem em suas próprias comunidades e nos sistemas econômicos, biológicos, culturais e políticos nos quais estão inseridos. Ademais, os problemas socioambientais da atualidade incluem-se nos objetivos da educação ambiental, esta que se faz presente no ensino fundamental como proposta pedagógica ou inserida nos Projetos Políticos Pedagógicos (PPP) das unidades escolares, consistindo "na investigação educando-educador, no método científico a ser construído a partir das motivações dos educandos, dos seus contextos socioambiental e cultural e da apreensão do conhecimento [...]" (MEDINA, 1994, p. 41 apud FREIRE; NASCIMENTO; SILVA, 2006, p. 41).

Dentre esses documentos, alguns temas sociais urgentes foram escolhidos e denominados de Temas Transversais, abrangendo a Ética, o Meio Ambiente, a Orientação Sexual, a Pluralidade Cultural, a Saúde, o Trabalho e Consumo. A proposta do tema Meio Ambiente é inserir as questões ambientais nos objetivos, conteúdos e orientações didáticas de todas as disciplinas, no período de escolaridade exigido. Na esfera da educação ambiental, a Lei $\mathrm{n}$ 은 9.795/1999 estabeleceu e instituiu a Política Nacional de Educação Ambiental (PNEA), legalizando seus princípios no sistema educacional brasileiro, tornando-a objeto de políticas públicas em caráter permanente. Seu marco inicial foi a Lei n 6.938/1981, que incluiu a educação ambiental em todos os níveis do ensino formal. Outros programas também foram desenvolvidos para formalizar políticas de meio ambiente nas escolas e nos currículos, tais como o Programa Nacional de Educação Ambiental (ProNEA) e os Projetos de Educação Ambiental do MEC, caso da Educação Ambiental nas escolas, Educação de Chico Mendes e Educomunicação Ambiental. Por outro lado, no documento Educação Ambiental do Brasil, organizado pela Secretaria de Educação a Distância (SEED) e pelo MEC, afirma-se que não há sentido em se pensar a inserção da educação ambiental nas escolas sem que seja feita sua integração no currículo escolar. 


\section{Algumas análises envolvendo educação ambiental, sustentabilidade e meio ambiente nas escolas públicas}

$\mathrm{Na}$ análise efetuada por Ferreira (2011), em tese de doutoramento envolvendo escolas estaduais paulistas, o MEC, por exemplo, considera que a situação da educação ambiental nas secretarias municipais é mais frágil que nas estaduais. Aliás, poucas são aquelas que a incluem como tratamento transversal nos currículos. Segundo a autora, nas secretarias municipais e estaduais, a maioria dos projetos e ações em educação ambiental é determinada pelas parcerias com órgãos ambientais e ONGs, demonstrando o pouco espaço a ela atribuído na estrutura organizacional dessas instituições, sendo inserida em projetos especiais desenvolvidos pelas secretarias em parceria com instituições externas. No processo em fazer (ou não) parte dos currículos, a educação ambiental incorporou diferentes propostas em meio à organização do processo educacional e do contexto sócio-histórico brasileiro.

Formou-se, desse modo, uma discussão em torno daqueles que se mostram favoráveis à sua inclusão nos currículos e, de outro, aqueles que pretendem justificar uma abordagem transversal $e$, por que não interdisciplinar - dessas questões em sala de aula. A própria discussão dos PCN ocorreu sobre amplas vertentes políticas, sociais, econômicas e históricas, suscitando, no Brasil, os debates globais sobre as questões socioambientais, caso dos conteúdos expressos nesses documentos. Ferraz (2008), que investigou a educação ambiental em escolas públicas do ensino fundamental de Ubatuba, no litoral paulista, analisou alguns pontos relativos aos prós e aos contras em adotar as questões ambientais na forma transversal ou como componente disciplinar. Em sua tese de doutorado, a autora entende que explorar a temática ambiental apenas como atividade extracurricular é o mesmo que minimizar sua relevância, pouco contribuindo para a formação de sujeitos comprometidos com o meio ambiente, incapazes, portanto, de se tornarem responsáveis pela construção de relações justas e equilibradas no âmbito socioambiental (FERRAZ, 2008).

Ayres (2007), ao observar as práticas de educação ambiental em escolas públicas do município de Maceió, Alagoas, comenta que, a despeito do que preconizam os documentos oficiais, essas práticas não se efetivam nem na perspectiva de um trabalho transversal nem na forma interdisciplinar. Em sua dissertação de mestrado, o autor pondera que a ausência de transversalidade e de interdisciplinaridade contribui para que as práticas de educação ambiental nas escolas, quando existem, sejam sempre isoladas, descontextualizadas, pontuais ou mesmo destinadas a um conteúdo conservador e simplista, o que acaba esvaziando "o sentido mais amplo, tanto da Educação Ambiental, enquanto atividade interdisciplinar e transversal, quanto da construção da 'Nova Cidadania' emancipatória a que se propõe” (AYRES, 2007, p. 21).

Araújo (2011), que realizou dissertação de mestrado com a proposta de construir projetos de trabalho como estratégia de ensino e aprendizagem em uma escola pública do Recife, Pernambuco, na perspectiva da complexidade,

revista brasileira educação ambiental 
afirma que o modelo vigente de escola propõe um ensino com disciplinas estanques e isoladas em detrimento de uma discussão afinada com a realidade socioambiental constituída por pluralidades complexas. Para o autor, isso significa dizer que a escola não tem conseguido formar seus alunos para serem capazes de interpretar, agir e intervir de forma comprometida e responsável com a natureza. Assim, o aluno acaba não encontrando na escola as possíveis respostas para as preocupações com suas vidas e o meio ambiente. Caramello (2012), ao investigar como as questões socioambientais têm sido desenvolvidas nas escolas paulistas, em especial no decorrer do ensino de física, constatou que, no ensino fundamental, as mesmas são sugeridas apenas por meio do Tema Transversal de Meio Ambiente. A autora também analisou os livros didáticos do ensino médio, tidos como referenciais utilizados pelos professores. Observou que há uma intenção, por parte desses indivíduos, em discutir os assuntos socioambientais em sala de aula. Em muitos casos, porém, essa preocupação revela pouco aprofundamento conceitual, pautando-se, sobretudo, no que diz a mídia e os currículos escolares.

Em sua tese de doutoramento, Caramello (2012) confirmou uma visão limitada dos problemas socioambientais nos contextos escolares, decorrente, em grande medida, da ausência de uma discussão mais aprofundada por parte dos alunos sobre suas próprias vivências e também por não serem explicitados os elementos necessários para se tratar a complexidade dos fenômenos. $\mathrm{Na}$ ideia da autora, a problemática socioambiental ainda apresenta, nos espaços escolares e na esfera da educação ambiental, uma visão fragmentada e insuficiente, tendo em vista não ser inserida nas discussões sobre a complexidade da realidade vivida por alunos e professores. Recorda-se que a complexidade da realidade em que se vive inclui princípios, noções e modos de se refletir sobre o exercício individual e coletivo da cidadania, emergindo as contradições e potencialidades de cada sujeito nesse processo formativo.

A partir desses vieses, levando em conta algumas das discussões iniciais sobre as questões socioambientais nas escolas, bem como uma educação com foco na cidadania, cita-se também o documento das Diretrizes Curriculares de Educação Ambiental das Escolas da Rede Municipal de Salvador, Bahia, elaborado por Freire, Nascimento e Silva (2006). As autoras classificam as atividades de educação ambiental em duas vertentes de abordagem: ecológico-preservacionista e socioambiental. Na primeira, a educação ambiental tem como eixo principal a conservação da natureza, sem maior aprofundamento teórico-metodológico dos problemas econômicos e sociais ligados às questões ambientais. Dessa forma, indivíduos são formados para mudança de atitudes e de valores, devendo assumir novos significados e comportamentos éticos perante a natureza. Conforme as autoras, nessa vertente, os objetivos são intrínsecos à educação ambiental, na qual o conteúdo ecológico pode auxiliar a dirimir os níveis de degradação ambiental causada pela ação do homem. Transformar a relação indivíduo/natureza contribui para que sejam solucionados os problemas ambientais. 
Por outro lado, a abordagem socioambiental possui foco na educação de caráter permanente, dialogando com os valores éticos e com os conhecimentos historicamente produzidos pela humanidade, o que implica uma preocupação direta com o futuro (FREIRE; NASCIMENTO; SILVA, 2006). Professores e alunos devem estar inseridos em práticas que não se desvinculem de suas realidades socioambientais, relacionando as diversas dimensões que compõem essa problemática, tais como a ecológica, econômica, científica, cultural e social. Para as autoras, a ideia é problematizar questões e interesses de forma não fragmentada ou reducionista, buscando alternativas viáveis para essa transformação, seja por meio da inter/multidisciplinaridade, seja pelas relações dialógicas desenvolvidas em sala de aula. Deduz-se que a tarefa se mostra árdua, complexa e incerta, sobretudo em se tratando de diferentes visões de mundo e da aparente necessidade em organizar alternativas educacionais que incorporem as dimensões da problemática socioambiental na construção de novos caminhos para uma cidadania plena e participativa.

Dias e Carneiro (2012), que elaboraram um estudo sobre as possibilidades de formação da cidadania socioambiental entre alunos do ensino fundamental no estado do Paraná, por meio do projeto Cidadão Ambiental Mirim, afirmam que as crianças - consideradas sujeitos da formação escolar devem iniciar a reflexão sobre os problemas socioambientais de forma a relacioná-los com a sua própria realidade local. Com base no nível de ensino, é possível perceber o que pode ser de fato um benefício ou um dano ao meio ambiente, as formas de interação e as "interdependências dos elementos do meio, as causas e consequências dos problemas socioambientais, assim como as possíveis alternativas de soluções para prevenir e solucionar problemas" (DIAS; CARNEIRO, 2012, p. 8). Os autores apontaram algumas considerações relevantes sobre a aplicação do projeto, nos dois últimos anos de sua efetivação.

Segundo Dias e Carneiro (2012), apesar do projeto dar ênfase em uma proposta de educação ambiental cidadã, a abordagem dos conteúdos nas escolas contempladas ainda é marcada por uma verve tradicional e conservacionista, predominantemente naturalista, pouco destacando as relações humanas com a natureza. Mostrou-se contrária aos próprios objetivos do projeto, que seriam o de estimular a cidadania dos sujeitos alunos a partir do entendimento das questões ambientais locais e a formação de ações como a cooperação, a responsabilidade, o cuidado e a solidariedade para com 0 meio em sua totalidade. Ainda assim, foi possível ressaltar a sua importância nos planejamentos escolares, desde os interesses das escolas à conexão empreendida entre os problemas socioambientais vivenciados pelos alunos e os sujeitos das comunidades do entorno.

Recorre-se também ao aprofundamento teórico-metodológico da complexidade moriniana que foi efetuado por Viégas (2010), ao investigar a complexidade da realidade socioambiental a partir dos contextos escolares no estado do Rio de Janeiro. Para Viégas (2010), a realidade socioambiental - a qual designa como metassistema socioambiental - contém elementos da

revista brasileira educação ambiental 
natureza e da sociedade, em múltiplos processos interativos de organização e desorganização do e no próprio sistema. A autora defende a existência de uma dicotomia latente nos contextos escolares analisados, manifestando-se, por um lado, como um limitante compreensivo de uma visão de mundo que é, em essência, técnico-científica, cartesiana, reducionista e disjuntiva, ou seja, que separa, fragmenta e reduz; e, por outro, um poder do grupo social sobre a natureza, emergido como sentimento e discurso da relação sociedade e natureza.

$\mathrm{Na}$ esfera da complexidade, a problemática socioambiental relaciona-se com os fatores internos e externos desses contextos, fazendo com que novas transformações sejam processadas concomitantemente ao conhecimento gerado e produzido. Conforme Viégas (2010), se o conhecimento gerado for de domínio sobre a natureza, já que resultante de uma lógica reducionista e disjuntiva, mais difícil será o caminho para a transformação do status quo, exigindo-se que estejam implícitos os processos subjugadores e emancipadores do (e no) metassistema socioambiental. Também a dimensão política deve se fazer presente.

No paradigma da complexidade, esses problemas ampliam-se para a tomada de decisões, integrando diversas áreas. Para Moraes (2010), diante da multiplicidade e heterogeneidade de diferentes experiências educacionais na contemporaneidade, é importante que se supere a fragmentação disciplinar e que se considere a presença do diálogo profícuo entre as mesmas. Essa crítica recai no modelo rígido de currículo que apresenta caráter disciplinar e fragmentado. Segundo Moraes (2010), currículo vem do latim Curriculum, significando trajetória ou percurso, bem como travessia, com pontos de partida e chegada. O currículo agrega a filosofia escolar, as ideologias, a diversidade de conhecimentos e as experiências educativas. Conforme Moraes (2010, p. 4), o currículo constitui-se em um caminho a seguir, que deveria "estar sujeito ao imprevisto, ao inesperado; sujeito às situações emergentes, ao acaso, à ecologia da ação, o que na maioria das vezes não acontece".

Assim, em um contexto curricular mais atento às diferenças e aos problemas da humanidade, cada disciplina deveria começar a interagir umas com as outras, intercambiando ideias e conceitos, epistemologias e metodologias, favorecendo o surgimento da interdisciplinaridade e da transdisciplinaridade, pois "ambas permitem uma releitura crítica da lógica disciplinar organizadora da maioria dos currículos existentes" (MORAES, 2010, p. 11). Depreende-se, portanto, que a interdisciplinaridade e a transdisciplinaridade sejam um desses caminhos de abertura ao diálogo.

\section{Considerações finais}

Diante do que foi exposto no texto, na premência dos argumentos destacados pelos autores citados, e ainda tendo em vista as propostas contidas nos documentos oficiais da educação pública, como os PCN e os 
Temas Transversais, torna-se importante enfatizar dois aspectos: primeiramente, a complexidade da realidade socioambiental tem sido abordada de modo insuficiente, fragmentado e descontextualizado das discussões sobre cidadania nas escolas; em segundo, a educação ambiental, tida como práxis emancipatória e transformadora de sujeitos, comprometida com uma educação cidadã e as questões ambientais da atualidade, não tem sido capaz de incorporar a integralidade da problemática socioambiental vivenciada pelas comunidades escolares. No que pontuam essas constatações, e crendo na proposta interdisciplinar como uma das possíveis vias teórico-metodológicas que pode se fazer presente em sala de aula, reconhece-se, contudo, que constitui um imenso desafio socializar conhecimentos interdisciplinares sobre os problemas socioambientais nas escolas públicas ao tempo em que se reivindicam ações voltadas para o exercício crítico da cidadania, exigindo-se mudanças implícitas do sistema.

Sendo assim, com destaque para visões não reducionistas e fragmentadas, retoma-se a análise da teoria da complexidade efetuada por Petraglia (2008). A autora comenta que se faz necessária uma reformulação do conceito chave de cidadania, que associa noções de identidade, liberdade e comunidade, mas que também compreende o sentido da democracia cognitiva, ao permitir o acesso ao conhecimento que não esteja encarcerado entre áreas disciplinares ou entre muros de instituições educacionais. Algumas das indagações de Petraglia (2008) se fazem pertinentes no contexto aqui discutido. Afinal, quem seria mesmo esse sujeito a quem é dada a função de construtor do conhecimento, "autor de sua própria história e capaz de conquistar a sua cidadania? Será que este sujeito poderá enfrentar os desafios do seu tempo? Poderá ser livre e feliz com a passagem do tempo e na convivência com as incertezas?" (PETRAGLIA, 2008, p. 34).

Essas questões são lançadas concomitantemente à expectativa de que possíveis desdobramentos teórico-metodológicos resultem em novas frentes de investigação. Apesar das dificuldades de toda ordem nos sistemas de ensino, dentre as quais a fragmentação do conhecimento em disciplinas que não se comunicam entre si, espera-se construir e difundir nas escolas públicas uma cidadania mais aberta, plural, multidimensional e cognitiva, sem desconsiderar suas estreitas e imprescindíveis relações com a educação ambiental, a sustentabilidade e o meio ambiente.

\section{Agradecimentos}

À Fundação de Amparo à Pesquisa do Estado da Bahia (FAPESB), pelo apoio financeiro concedido em forma de bolsa durante a realização do doutorado do qual esta pesquisa faz parte. Ao Programa de Pós-Graduação em Difusão do Conhecimento (DMMDC) da Faculdade de Educação da Universidade Federal da Bahia (FACED-UFBA), por ter tornado possível o doutoramento desta autora. 


\section{Referências}

ARAÚJO, A.F. Projetos de trabalho e educação ambiental: uma estratégia de ensino e aprendizagem sob a perspectiva da complexidade. 2011. $141 \mathrm{f}$. Dissertação (Mestrado em Ensino das Ciências) - Programa de PósGraduação da Universidade Federal Rural de Pernambuco, Recife, 2011.

AYRES, F.G.S. Cidadania e educação ambiental na interpretação do docente de educação fundamental no município de Maceió-Alagoas. 2007. 125 f. Dissertação (Mestrado em Desenvolvimento e Meio Ambiente) - Programa de Pós-Graduação da Universidade Federal de Alagoas, Maceió, 2007.

BRASIL. Secretaria de Educação Fundamental. Parâmetros Curriculares Nacionais: terceiro e quarto ciclos do ensino fundamental: introdução aos parâmetros curriculares nacionais. Brasília: MEC/SEF, 1998a.

BRASIL. Secretaria de Educação Fundamental. Temas Transversais: meio ambiente. Brasília: MEC/SEF, 1998b.

CARAMELLO, G.W. Aspectos da complexidade: contribuições da Física para compreensão do tema ambiental. 2012. 250 f. Tese (Doutorado em Ensino de Ciências) - Programa de Pós-Graduação do Instituto de Física e da Faculdade de Educação da Universidade de São Paulo, São Paulo, 2012.

COSTA, G. Ciência, tecnologia e sustentabilidade socioambiental. Revista Científica Hermes 1, p. 19-29, 2009.

DEMO, P. Pesquisa e construção do conhecimento: metodologia científica no caminho de Habermas. 4. ed. Rio de Janeiro: Tempo Brasileiro, 2000.

DIAS, D.S.S.; CARNEIRO, S.M.M. Contribuições para a formação da consciência socioambiental cidadã nos anos iniciais do ensino fundamental. In: SEMINÁRIO DE PESQUISA EM EDUCAÇÃO DA REGIÃO SUL - ANPED SUL. 9. 2012. Anais eletrônicos... Disponível em: <http://www.portalanpedsul.com.br/admin/uploads/2012/Educacao Ambiental/T rabalho/05 5343 237-7474-1-PB.pdf > Acesso em: 20 jun. 2013.

DIEGUES, A.C. Sociedades e comunidades sustentáveis. São Paulo: NUPAUB-USP, 2003.

FENZL, N.; MACHADO, J.A.C. A sustentabilidade de sistemas complexos: conceitos básicos para uma ciência do desenvolvimento sustentável: aspectos teóricos e práticos. Belém: NUMA/UFPA, 2009.

FERRAZ, M.L.C.P. Sustentabilidade das escolas municipais de Ensino Fundamental: estudo de caso em Ubatuba, Estado de São Paulo, Brasil. 2008. 300 f. Tese (Doutorado em Ciência Ambiental) - Programa de Pós-Graduação da Universidade de São Paulo, São Paulo, 2008. 
FERREIRA, C.E.A. O meio ambiente na prática de escolas públicas da rede estadual de São Paulo: intenções e possibilidades. 2011. 177 f. Tese (Doutorado em Educação) - Programa de Pós-Graduação da Universidade de São Paulo, São Paulo, 2011.

FREIRE, P. Pedagogia do oprimido. 17 ed. Rio de Janeiro: Paz e Terra, 1987.

FREIRE, J.T.O; NASCIMENTO, M.F.F.; SILVA, S.A.H. Diretrizes Curriculares de Educação Ambiental: as escolas da Rede Municipal de Ensino de Salvador. Salvador: SMEC, 2006.

FÓRUM INTERNACIONAL DE ORGANIZAÇÕES NÃO GOVERNAMENTAIS E MOVIMENTOS SOCIAIS. Tratado de Educação Ambiental para sociedades sustentáveis e responsabilidade global. In: Tratado das ONGs; aprovado no Fórum Internacional de Organizações Não Governamentais e Movimentos Sociais, no Âmbito do Fórum Global ECO-92. Rio de Janeiro: Eco, 1992, p. 193-196.

GALEFFI, D. Saberes plurais e difusão do conhecimento em educação: uma perspectiva transdisciplinar. In: GURGEL, P.R.H.; SANTOS, W.N.(Org.). Saberes plurais, difusão do conhecimento e práxis pedagógica. Salvador: EDUFBA, 2011. p. 15-47.

GIL, A.C. Métodos e técnicas de pesquisa social. 5 ed. São Paulo: Atlas.

GUDYNAS, E. Ecología, Economía y Etica del desarrollo sostenible. 5. ed. Montevideo: Coscoroba, 2004.

JACOBI, P. Educação ambiental: o desafio da construção de um pensamento crítico, complexo e reflexivo. Educação e Pesquisa, São Paulo, v. 31, n. 2, p. 233-250, maio/ago. 2005.

LEFF, E. Complexidade, interdisciplinaridade e saber ambiental. Olhar de professor. Ponta Grossa, 14 (2), p. 309-335, 2011.

LIMA, G.F.C. Educação ambiental crítica: do socioambientalismo às sociedades sustentáveis. Educação e Pesquisa, São Paulo, v. 35, n. 1, p. 145-146, jan./abr. 2009.

LIMA, G.F.C. Crise ambiental, educação e cidadania: os desafios da sustentabilidade emancipatória. In: LOUREIRO, C.F.B.; LAYRARGUES, P.P.; CASTRO, R.S. (Orgs.). Repensando o espaço da cidadania. 5. ed. São Paulo: Cortez, 2011. p. 115-148.

LOUREIRO, C.F.B et al. (Org.). Cidadania e meio ambiente. Construindo os Recursos do amanhã, v. 1. Salvador: Centro de Recursos Ambientais, 2003.

LOUREIRO, C.F.B et al. Complexidade e dialética: contribuições à práxis política e emancipatória em educação ambiental. Educ. Soc., v. 26, n. 93, p. 1473-1494, set./dez. 2005. 
MORAES, M.C. Complexidade e currículo: por uma nova relação. Polis, n. 25, 2010.

MORIN, E. Os sete Saberes Necessários à Educação do Futuro. 2. ed. São Paulo: Cortez; Brasília, DF: UNESCO, 2000.

MORIN, E. A cabeça bem feita: repensar a reforma, reformar o pensamento. 8. ed. Trad. Eloá Jacobina. Rio de Janeiro: Bertrand Brasil, 2003.

OLIVEIRA, A.C.D.C. et al. A cidadania infanto-juvenil em questão: o Programa de Formação em Cidadania infanto-juvenil no contexto do socioambientalismo. In: CONGRESSO BRASILEIRO DE SOCIOLOGIA. 13. 2007. Recife. Anais eletrônicos... Recife: CBS, 2007. Disponível em:

$<$ http://www.sbsociologia.com.br/portal/index.php?option=com docman\&task=C at view\&gid=156\&ltemid=171 > Acesso em: 14 dez.. 2012.

PETRAGLIA. I.C. Educação complexa para uma nova política de civilização. Educ. rev., Curitiba, n. 32, p. 29-41, 2008.

SEVERO, C.G. Sobre a formação da cidadania nos documentos oficiais e nos materiais didáticos e a importância dos gêneros discursivos. Odisséia, n. 1, p. 1-14, 2008.

STEINBRENNER, L.G. Direito ambiental e ecocidadania: alguns elementos da teoria da complexidade. 2011. 106 f. Dissertação (Mestrado em Desenvolvimento) - Programa de Pós-Graduação da Universidade Regional do Noroeste do Estado do Rio Grande do Sul, ljuí, 2011.

VIÉGAS, A. Educação ambiental e complexidade: uma análise a partir do contexto escolar. 2010. 288 f. Tese (Doutorado em Psicossociologia de Comunidades e Psicologia Social - EICOS) - Programa de Pós-Graduação da Universidade Federal do Rio de Janeiro, Rio de Janeiro, 2010. 